
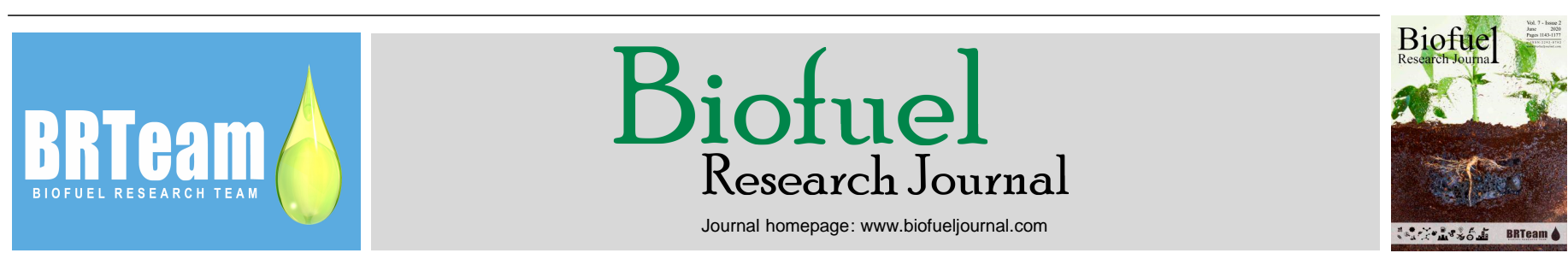

Original Research Paper

\title{
Genomic and metabolic insights into solvent production by Thermoanaerobacterium thermosaccharolyticum GSU5
}

\author{
Rocío Díaz Peña, Daniela Alvarez, Diego Egoburo, Jimena Ruiz ${ }^{\dagger}$ M. Julia Pettinari*
}

Departamento de Química Biológica, Facultad de Ciencias Exactas y Naturales, Universidad de Buenos Aires, IQUIBICEN-CONICET, Buenos Aires, Argentina.

\section{HIGHLIGHTS}

$>$ Comparative genome analysis of Thermoanaerobacterium thermosaccharolyticum GSU5 was performed.

$>$ Ethanol and butanol production from different carbon sources without acetone was achieved.

$>$ Solventogenic and acidogenic pathways in

Thermoanaerobacterium were elucidated.

\section{GRAPHICAL ABSTRACT}

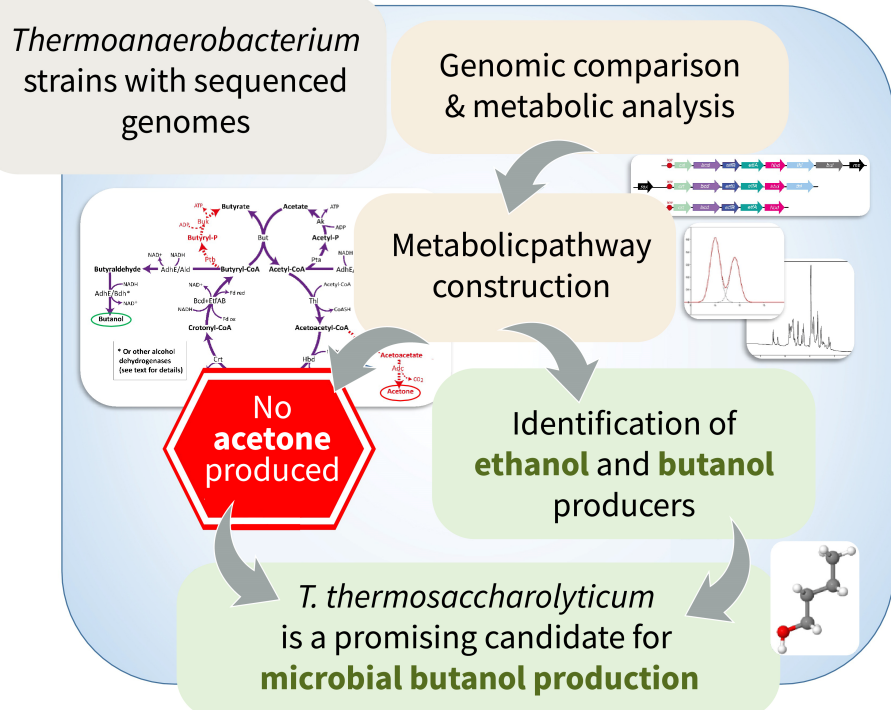

\section{ARTICLE INFO}

\section{Article history:}

Received 23 December 2019

Received in revised form 3 February 2020

Accepted 1 March 2020

Available online 1 June 2020

\section{Keywords:}

Butanol

Ethanol

Butyrate

Second-generation biofuels

Genomic analysis

\begin{abstract}
Thermoanaerobacterium thermosaccharolyticum GSU5 was isolated from animal dung collected in a pasture plain in Buenos Aires, Argentina. This thermophilic and anaerobic microorganism was able to produce butanol and ethanol, but not acetone, using sugars such as xylose, arabinose, glucose, galactose, fructose, sucrose, and cellobiose. Key metabolic enzymes leading to solvent production were identified in its genome. A detailed analysis of the solvent and organic acid biosynthetic pathway genes of sequenced strains revealed new insights into the unique metabolic features of this species. Genes required for the synthesis of acetone are absent in the genomes of all sequenced Thermoanaerobacterium, suggesting that it is a general trait of the genus. Strains able to produce butanol synthesize butyrate through the one step pathway catalyzed by the butyryl-CoA:acetate-CoA transferase (But). The large range of fermentable substrates and the ability to produce both ethanol and butanol without acetone makes this species an interesting candidate for second generation biofuel production.
\end{abstract}

(c) 2020 BRTeam. All rights reserved.

* Corresponding authors at: Tel.: +541145763334

E-mail address: jul@qb.fcen.uba.ar

† Present address: Instituto de Investigaciones en Biociencias Agrícolas y Ambientales, INBA-CONICET, Facultad de Agronomía, Universidad de Buenos Aires, Buenos Aires, Argentina.

Please cite this article as: Díaz Peña R., Alvarez D., Egoburo D., Ruiz J., Pettinari M.J. Genomic and metabolic insights into solvent production by Thermoanaerobacterium thermosaccharolyticum GSU5. Biofuel Research Journal 26 (2020) 1149-1158. DOI: 10.18331/BRJ2020.7.2.3 


\section{Introduction}

Climate change is a threat to various forms of life on the planet Earth. This phenomenon is partially due to the preferential use of fossil fuels to sustain human activities such as heating, agriculture, or transportation. The use of biofuels is one of the most promising solutions, as it would help mitigate the effects of climate change by avoiding the use of non-renewable resources as sources of energy such as petroleum or natural gas (Hill et al., 2006).

Among the most common biofuels are alcohols that can be obtained from microbial fermentation using different kinds of carbon sources. Ethanol is the best known and most studied alcohol that can be obtained by microbial fermentation using yeast or bacteria. While butanol is a less common but it is an increasingly attractive biofuel due to several characteristics, i.e., producing more energy if properly harnessed, having lower vapor pressure, and being less hygroscopic than ethanol (Dürre, 2007).

The production of both ethanol and butanol along with acetone, also known as acetone-butanol-ethanol (ABE) fermentation process, has been extensively studied in several Clostridium species, such as C. acetobutylicum (Jones and Woods, 1986). Although most butanol producers are strictly anaerobic, the halophile Nesterenkonia sp. strain $\mathrm{F}$ has also been reported to produce $\mathrm{ABE}$ from glucose under aerobic conditions (Amiri et al., 2016).

Many different processes have been developed to obtain alcohols from sugars or starch, but the use of these substrates to produce biofuels would trigger a competition over arable land and irrigation water; inputs upon which food security depends. To avoid this problem, biofuels should be obtained from non-food substrates, such as lignocellulosic biomass.

Several different approaches have been employed to exploit this abundant substrate, most of which start with the hydrolysis of the biomass to obtain sugars that can be subsequently fermented into the desired compounds. This hydrolysis step is normally accomplished through energy intensive processes, involving high temperatures and aggressive chemical conditions.

Consolidated bioprocessing is an alternative that integrates enzyme production, saccharification and fermentation (Yamada et al., 2013) and can be achieved under mild conditions. Consolidated bioprocesses that use anaerobic thermophilic organisms capable of degrading lignocellulosic biomass are expected to more effectively meet the sustainability standards, as they would enable production of biofuels from renewable resources by means of low energy demanding procedures (Lynd et al., 2002).

The use of thermophilic cellulolytic bacteria, such as C. thermocellum, has been extensively studied for the production of ethanol from cellulose (Lamed and Zeikus, 1980; Tian et al., 2016). However, most of these organisms are unable to produce butanol, and/or to ferment pentoses derived from hemicellulose degradation, thereby limiting the efficient use of lignocellulosic biomass (Demain et al., 2005).

In recent years, several species of the thermophilic genus Thermoanaerobacterium have received increased attention due to their capability to use different biomass substrates to produce solvents. The genus Thermoanaerobacterium comprises 8 validly described species: $T$. aciditolerans, T. aotearoense, T. saccharolyticum, T. thermosaccharolyticum, $T$. thermostercoris (formerly $T$. thermostercus), $T$. thermosulfurigenes, $T$. xylanolyticum, and T. butyriciformans (Onyenwoke and Wiegel, 2015). T. saccharolyticum and $T$. thermostercoris can produce ethanol (Shaw et al., 2008; Romano et al., 2010) while several T. thermosaccharolyticum isolates have been reported to produce hydrogen (Cao et al., 2009) and/or butanol (Li et al., 2018) from different biomass sources.

These results point out the potential of these microorganisms for the synthesis of diverse bioproducts, and particularly biofuels, from untreated or minimally treated biomass, and encourage further research in order to analyze their potential application in consolidated bioprocesses.

In light of the above, we have isolated and characterized a new strain, $T$. thermosaccharolyticum GSU5, an anaerobic thermophilic bacterium that is capable of producing ethanol and butanol from a variety of substrates. In this work, we present the genomic sequence of GSU5 and analyze its phenotypic traits, especially those pertaining to solvent production, in comparison with the type strain of the species. Additionally, genes related to solventogenesis of all sequenced Thermoanaerobacterium are compared to gain new insights into their unique metabolic properties.

\section{Materials and Methods}

\subsection{Bacterial strains and growth conditions}

Thermoanaerobacterium thermosaccharolyticum GSU5 was isolated from animal dung collected in a pasture plain in Buenos Aires, Argentina, in 1987. The strain was originally designated as Clostridium thermopapyrolyticum due to its phenotypic characteristics (Mendez et al. 1991). Stock cultures were kept at $4^{\circ} \mathrm{C}$ in Hungate tubes containing growth medium with a strip of filter paper for several decades. Thermoanaerobacterium thermosaccharolyticum DSM 571 was obtained from Deutsche Sammlung von Mikroorganismen und Zellkulturen (DSMZ, Germany).

Both strains were grown at $60^{\circ} \mathrm{C}$ in $5 \mathrm{~mL}$ screw cap tubes using the Hungate method (Hungate, 1950) in the Tryptose Sulphite Cycloserine (TSC) medium (Shaw et al., 2012) containing per liter: $2.0 \mathrm{~g}$ of sodium citrate tribasic dihydrate, $1.85 \mathrm{~g}$ of $(\mathrm{NH} 4)_{2} \mathrm{SO}_{4}, 0.1 \mathrm{~g}$ of $\mathrm{FeSO}_{4} .7 \mathrm{H}_{2} \mathrm{O}, 2.0 \mathrm{~g}$ of $\mathrm{MgSO}_{4} .7 \mathrm{H}_{2} \mathrm{O}, 1.0 \mathrm{~g}$ of $\mathrm{KH}_{2} \mathrm{PO}_{4}, 0.1 \mathrm{~g}$ of $\mathrm{CaCl}_{2.2} \mathrm{H}_{2} \mathrm{O}, 2 \mathrm{mg}$ of resazurin $8.5 \mathrm{~g}$ of yeast extract, and $10 \mathrm{~g}$ of glucose. The $\mathrm{pH}$ was adjusted to 6.7 with $\mathrm{NaOH} 10 \mathrm{M}$.

For metabolite production analysis, the strains were grown in the TSC medium supplemented with $10 \mathrm{~g} / \mathrm{L}$ of different carbon sources: monosaccharides xylose, arabinose, glucose, galactose, and fructose; and disaccharides sucrose and cellobiose. The $\mathrm{pH}$ was adjusted to 6.7 with $\mathrm{NaOH} 10 \mathrm{M}$. The strains were grown at $60^{\circ} \mathrm{C}$ for $48 \mathrm{~h}$.

Fermentations were performed in a $2.5 \mathrm{~L}$ Biostat A bioreactor with $1.5 \mathrm{~L}$ of the TSC supplemented with $10 \mathrm{~g} / \mathrm{L}$ of carbon sources (glucose or xylose) After $17 \mathrm{~h}, 5 \mathrm{~g} / \mathrm{L}$ of the corresponding sugar were added to avoid carbon source depletion. The agitation was kept at $100 \mathrm{rpm}$. The $\mathrm{pH}$ was adjusted initially at 7 and was regulated with $\mathrm{NaOH} 2 \mathrm{M}$ and $\mathrm{H}_{2} \mathrm{SO}_{4} 1 \mathrm{M}$ to keep it over 5. TSC pre-cultures were grown in serum bottles containing $50 \mathrm{~mL}$ of the medium at anaerobic conditions and $150 \mathrm{~mL}$ of inoculum was added to the bioreactor $(\mathrm{DO}=0.3)$. The strains were grown at $60^{\circ} \mathrm{C}$ for $35 \mathrm{~h}$.

\subsection{Sequence analysis}

The sequence was obtained using a whole-genome shotgun strategy with a Roche 454 GS FLX Titanium pyrosequencer at INDEAR, Argentina, achieving $\sim 37$-fold coverage. Assembly was done using the Newbler version 2.6 and generated 73 contigs, the largest of which had 81,110 bases. The annotation was performed using the NCBI Prokaryotic Genomes Automatic Annotation Pipeline (PGAAP) and Rapid Annotations using Subsystems Technology (RAST) (Overbeek et al., 2014). The genome of the GSU5 was deposited in the Genbank with the accession number of MINB01000001-MINB01000073.

Genome to genome distance calculations were performed using the GGDC program (https://ggdc.dsmz.de/), that provides an in silico estimation of DNA-DNA hybridization (DDH) values (Auch et al., 2010) and Average Nucleotide Identity based on blast (ANIb) (http://jspecies.ribohost.com/jspeciesws) (Richter et al., 2016).

\subsection{Analytical determinations}

Cultures were centrifuged for $5 \mathrm{~min}$ at $6000 \mathrm{rpm}$, the supernatants were filtered through $0.22 \mu \mathrm{m}$ nylon membranes (MSI, USA) and stored at $-20^{\circ} \mathrm{C}$ for analytical determinations.

Organic acids were determined by a high-performance liquid chromatography (HPLC) using an LC-20AT Prominance equipment (Shimadzu Corp., Kyoto, Japan) with an HPX-87-H Aminex column (Cat no. 125- 170 0140; Bio Rad Laboratories Inc., Hercules, CA) at $50^{\circ} \mathrm{C}$. The mobile phase consisted of $5 \mathrm{mM}$ sulfuric acid at a flow rate of $0.6 \mathrm{~mL} / \mathrm{min}$. The metabolites were quantified with an SPD-20AV UV detector (Shimadzu 171 Corp.).

Ethanol and butanol were measured using an Agilent 7820A GC-FID with manual head space injection. The separation was conducted on a HPINNO- WAX capillary column $(30 \mathrm{~m}, 0.25 \mu \mathrm{m}$ film thickness and $0.25 \mathrm{~mm}$ ID). 
The supernatants were diluted by adding 1 volume of $\mathrm{K}_{2} \mathrm{CO}_{3} 1 \mathrm{~g} / \mathrm{mL}$, while $5 \mu 1$ of isobutanol $5 \mathrm{~g} / \mathrm{L}$ were added as an internal standard. The samples were heated at $60^{\circ} \mathrm{C}$ for $1 \mathrm{~h}$ and $1 \mathrm{~mL}$ of the gas phase was injected manually in a GC-FID. The GC oven was initially heated at $35^{\circ} \mathrm{C}$ for $2 \mathrm{~min}$, then to $45^{\circ} \mathrm{C}$ at a rate of $3^{\circ} \mathrm{C} / \mathrm{min}$ and was held at this temperature for $1 \mathrm{~min}$. Finally, the temperature was increased to $120^{\circ} \mathrm{C}$ at a rate of $5^{\circ} \mathrm{C} / \mathrm{min}$. The injector and FID temperatures were set at 150 and $300^{\circ} \mathrm{C}$, respectively. Nitrogen was used as the carrier gas at a column flow of $2 \mathrm{~mL} / \mathrm{min}$ with a $5: 1$ split ratio. The chromatographic method was validated for the experimental conditions used. The method was found to be precise and accurate on statistical evaluation with a linearity range of 0.01 to $1 \mathrm{~g} / \mathrm{L}$. The limit of quantification $(\mathrm{LOQ}=0.004 \mathrm{~g} / \mathrm{L})$ and limit of detection $(\mathrm{LOD}=0.0002 \mathrm{~g} / \mathrm{L})$ were also adequate.

\section{Results and Discussion}

\subsection{Genomic relatedness of T. thermosaccharolyticum GSU5}

The draft genome sequence of $T$. thermosaccharolyticum GSU5 was obtained in 73 contigs with a total length of $2.7 \mathrm{~kb}$, with a mean $\mathrm{G}+\mathrm{C}$ content of 33.9\%. Analysis of the genome using the NCBI Prokaryotic Genomes Automatic Annotation Pipeline (PGAAP) revealed 2668 genes, comprising 2501 predicted coding regions, 102 pseudogenes, and 65 RNA genes, including one 16S rRNA gene. The RAST annotation covered 339 subsystems, including $44 \%$ of the coding sequences, and classified 897 open reading frames (ORFs) as hypothetical proteins.

Comparison of the 16S rRNA gene of GSU5 against sequences deposited in the Ribosomal Database Project revealed that GSU5 clusters together with other strains of T. thermosaccharolyticum and is closest to strain TG57 (Fig. 1). Strain SP-H2 could not be included in this analysis because the sequence of its rRNA gene is not available in spite of the fact that its genome has been sequenced.
The overall genomic phylogenetic relatedness of strain GSU5 with other strains of the genus Thermoanaerobacterium was analyzed through in silico genome comparisons. Values of in silico DDH between $87.30 \%$ and $71.6 \%$ were obtained when GSU5 was compared with $T$. thermosaccharolyticum strains TG57, DSM 571, M5, M0795, and SP-H2, indicating that it belongs to the T. thermosaccharolyticum species (species cutoff value: $70 \%$ ), while the values obtained with all other strains ranged between 26.40 and $24.20 \%$ (Table 1). When ANIb was calculated, the values obtained (96.28 98.04\%) when GSU5 was compared with other $T$. thermosaccharolyticum strains provided further evidence that it belongs to this species (species cutoff value: $95 \%$ ) (Table 1 ).

Among the 12 Thermoanaerobacterium genomes available, the best represented species is T. thermosaccharolyticum, with 6 sequenced strains, followed by $T$. saccharolyticum, with two strains, and a single representative each for T. xylanolyticum and T. aotearoense. The other two genomes correspond to strains RBIITD and PSU2. When the genome of Thermoanaerobacterium sp. RBIITD was compared against all strains of the genus Thermoanaerobacterium, DDH values ranged between 21.3 and 24.70\% and ANIb values ranged between 75.92 and 79.93\% (Table S1). Similar results were obtained for Thermoanaerobacterium sp. PSU2, with DDH values ranging from 21.30 and $58.30 \%$ and ANIb values between 76.68 and $94.20 \%$ (Table S2). These results indicate that these strains do not belong to any of the species with sequenced representatives: $T$. thermosaccharolyticum, $T$. saccharolyticum, $T$. xylanolyticum or $T$. aotearoense.

When strain PSU-2 was first described, it was classified as $T$. thermosaccharolyticum (Sompong et al., 2008). However, when its genome was published, the authors reported that it was not a strain of $T$. thermosaccharolyticum, and although it had a high homology with $T$. xylanolyticum, it did not belong to this species either (Sompong et al., 2017).

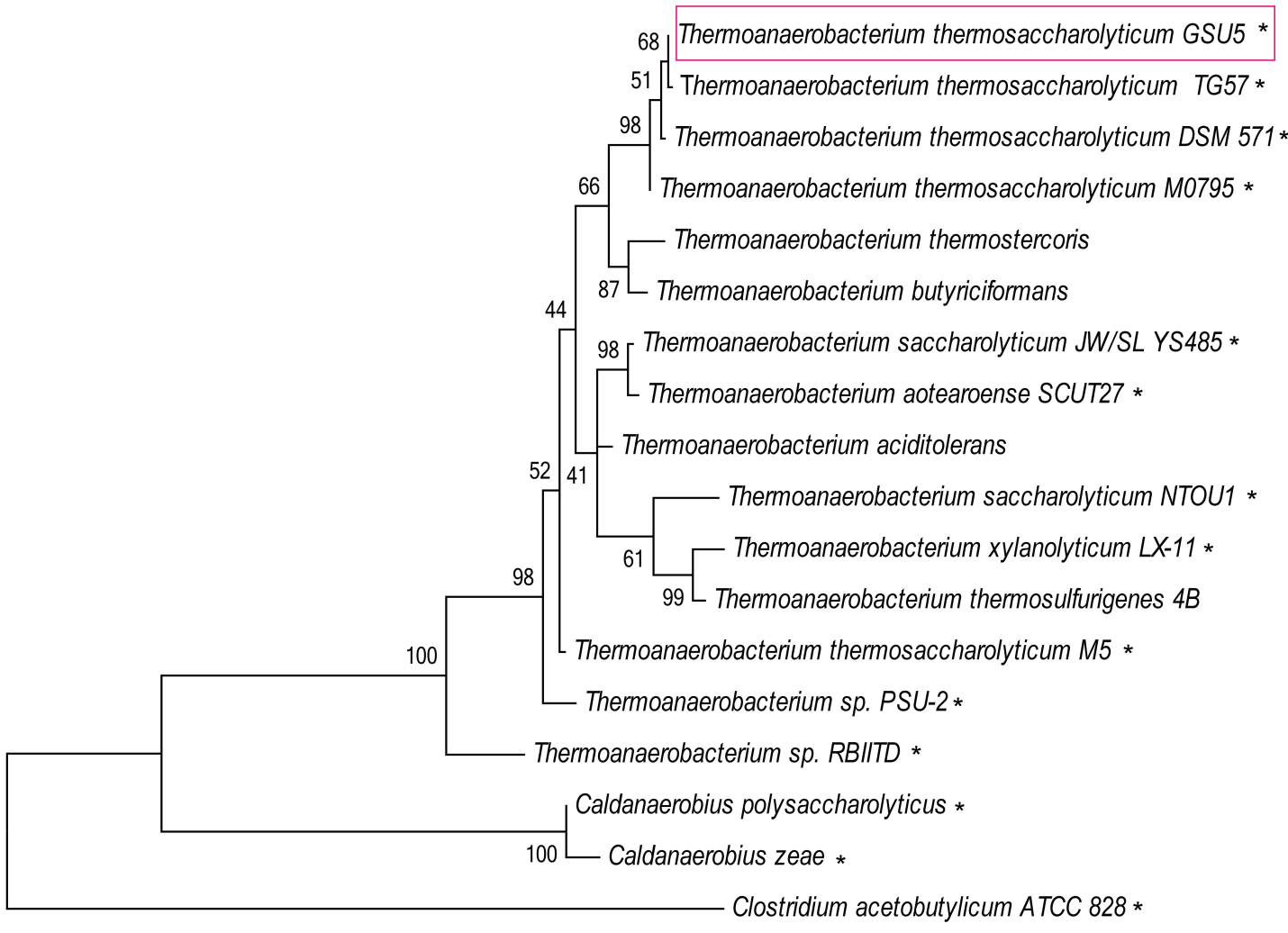

Fig. 1. Relatedness of GSU5 with other bacteria.

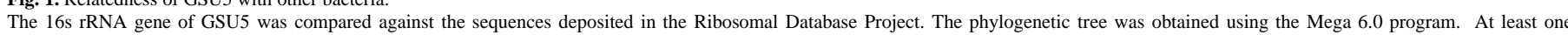

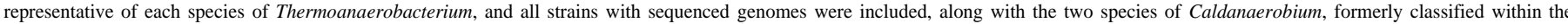
Thermoanaerobacterium genus. Clostridium acetobutylicum was used as an outgroup.

*Strains with sequenced genomes 
Table 1.

Genome to genome comparisons of GSU5 with other species of Thermoanaerobacterium.

\begin{tabular}{llcc}
\hline Strain & Accession number & DDH ${ }^{1}$ estimate & ANIb $^{2}$ \\
\hline T. thermosaccharolyticum GSU5 & MINB01000001-MINB01000073 & - & - \\
T. thermosaccharolyticum TG57 & CP016893.1 & $87.30 \pm 2.50 \%$ & $98.04 \%$ \\
T. thermosaccharolyticum DSM 571 & CP002171 & $76.40 \pm 2.88 \%$ & $96.48 \%$ \\
T. thermosaccharolyticum M5 & NKHD01000001-NKHD01000077 & $75.40 \pm 3.00 \%$ & $96.93 \%$ \\
T. thermosaccharolyticum M0795 & NC_019970 & $72.10 \pm 2.92 \%$ & $96.28 \%$ \\
T. thermosaccharolyticum SP-H2 & VWOK00000000.1 & $71.6 \pm 3.9 \%$ & $96.34 \%$ \\
T. saccharolyticum JW/SL-YS485 & CP003184.1 & $24.30 \pm 2.39 \%$ & $81.63 \%$ \\
T. saccharolyticum NTOU1 & BBKT01000001-BBKT01000101 & $26.40 \pm 2,50 \%$ & $83.52 \%$ \\
T. xylanolyticum LX-11 & CP002739.1 & $25.00 \pm 2.40 \%$ & $82.12 \%$ \\
T. aotearoense SCUT27 & AYSN01000000 & $24.20 \pm 2.50 \%$ & $81.76 \%$ \\
Thermoanaerobacterium sp. PSU-2 & MSQD00000000.1 & $24.40 \pm 2.50 \%$ & $81.82 \%$ \\
Thermoanaerobacterium sp. RBIITD & LT906662.1 & $24.30 \pm 2.50 \%$ & $79.52 \%$ \\
\hline${ }^{1}$ DNA-DNA hybridization (DDH) values were estimated using the Genome-to-Genome Distance Calculator 2.1 (Species \\
cutoff value: $70 \%)$.
\end{tabular}

The results presented in this work indicate that neither PSU2 nor RBIITD belong to T. saccharolyticum, T. thermosaccharolyticum, T. xylanolyticum or T. aotearoense. It remains to be studied whether these strains belong to species with no sequenced representatives, or to previously undescribed Thermoanaerobacterium species.

\subsection{Genetic analysis of solvent synthesis pathways}

A search for genes coding for the key enzymes involved in the synthesis of butanol, ethanol, and acetone was performed in the genome of GSU5 and all other sequenced Thermoanaerobacterium strains using the RAST annotation Server, BLAST and the Biocyc database collection in order to analyze the corresponding pathways.

As shown in Table 2, all genes coding for key enzymes of butanol synthesis were detected in GSU5, in all sequenced T. thermosaccharolyticum strains, and in Thermoanaerobacterium sp. RBIITD (locus tags in Table S3). In contrast, these genes were absent in $T$. xylanolyticum LX-11, T. saccharolyticum JW/SL-YS485, T. saccharolyticum NTOU1, T. aotearoense SCUT27, and Thermoanaerobacterium sp. PSU-2, which suggests that they are not capable of producing butanol (Table 2).

In all strains of $T$. thermosaccharolyticum, genes coding for the crotonase $(c r t)$, butyryl-CoA dehydrogenase $(b c d)$, electron transfer flavoprotein $(e t f A B)$, 3-hydroxybutyryl-CoA dehydrogenase $(h b d)$, and acetyl-CoA Cacetyltransferase $(t h l)$, are located in a cluster. Next to these genes and in the same orientation are but, that codes for a butyryl-CoA: acetate-CoA transferase, and rex, corresponding to a redox dependent transcriptional regulator (Fig. 2).
In the well-known butanol producer Clostridium acetobutylicum, seven of the genes are also in a genomic cluster (Berezina et al., 2009) named bcs operon, albeit with a different organization: in this organism thl is in a monocistronic operon located in a different region, rex is situated upstream from $\mathrm{crt}$, and but is absent (Fig. 2). In C. acetobutylicum, the transcriptiona regulator Rex plays a fundamental role in the regulation of solvent synthesis (Panitz et al., 2014) and binds to specific sequences identified upstream from three genes: $t h l$, crt (the first gene of the bcs operon), and $a d h E$ (Wietzke and Bahl, 2012). Putative binding sites for Rex (ROP: Rex operator site) were observed upstream from crt (Fig. 2) and $a d h E$ in the genome of GSU5, suggesting that Rex could regulate the expression of these genes in Thermoanaerobacterium.

In Thermoanaerobacterium sp. RBIITD, genes related to butanol formation have a different genetic organization, since $t h l$ is located in the bcs operon but rex is located upstream from crt (Fig. 2).

There are 5 genes encoding alcohol dehydrogenases distributed throughout the genome of GSU5 and one encoding an aldehyde dehydrogenase (ald). The gene coding for the bifunctional alcohol/aldehyde dehydrogenase $(a d h E)$ was detected in a monocistronic operon with a similar location in all genomes analyzed, while ald, corresponding to an aldehyde dehydrogenase, was only found in GSU5 and in some butanol producing and non-butanol producing strains (Table 2). $T$. thermosaccharolyticum DSM 571 and M5 produce both butanol and ethanol (Bhandiwad et al., 2013; Jiang et al., 2018; Li et al., 2018) but do not carry ald, suggesting that it is not essential for alcohol synthesis in Thermoanaerobacterium. This is in agreement with previous reports that

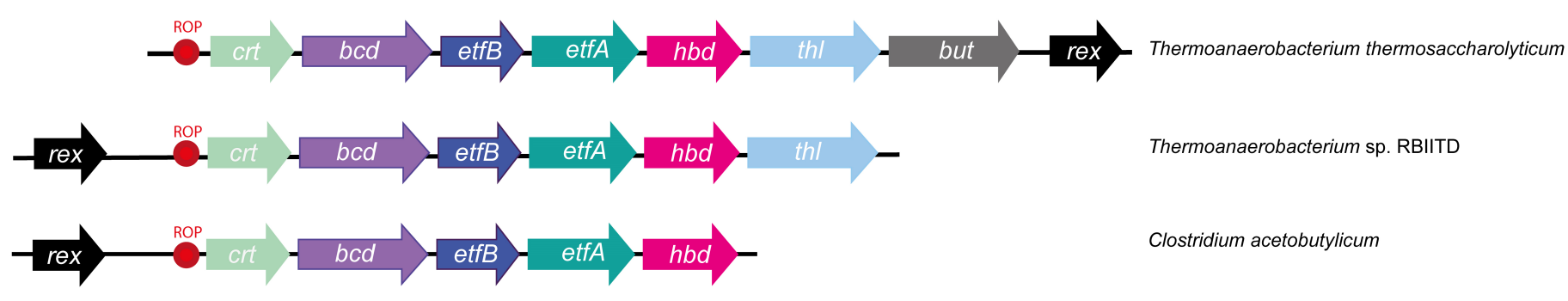

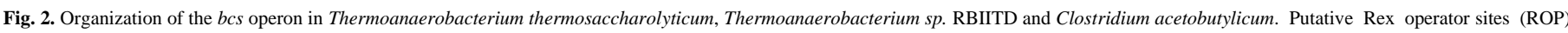
are indicated as red circles.

Please cite this article as: Díaz Peña R., Alvarez D., Egoburo D., Ruiz J., Pettinari M.J. Genomic and metabolic insights into solvent production by Thermoanaerobacterium thermosaccharolyticum GSU5. Biofuel Research Journal 26 (2020) 1149-1158. DOI: 10.18331/BRJ2020.7.2.3 
Table 2.

Genes involved in ethanol, butanol, and butyrate synthesis in the sequenced Thermoanaerobacterium strains.

\begin{tabular}{|c|c|c|c|c|c|c|c|c|c|c|c|c|c|c|c|c|c|c|c|c|}
\hline Strain & crt & bcd & etf $B$ & etf $A$ & $h b d$ & thl & but & ptb & buk & ald & adhI & $a d h 2$ & adh3 & bhd & $a d h E$ & pta & $a k$ & ctfA & ctfB & $a d c$ \\
\hline T. thermosaccharolyticum GSU5 & $100^{*}$ & 100 & 100 & 100 & 100 & 100 & 100 & & & 100 & 100 & 100 & 100 & 100 & 100 & 100 & 100 & & & \\
\hline T. thermosaccharolyticum TG57 & 100 & 100 & 99 & 100 & 100 & 100 & 100 & & & 58 & 100 & 99 & 99 & 99 & 99 & 99 & 99 & & & \\
\hline T. thermosaccharolyticum DSM 571 & 91 & 98 & 99 & 99 & 100 & 100 & 100 & & & & 99 & 99 & 100 & 99 & 99 & 99 & 99 & & & \\
\hline T. thermosaccharolyticum M5 & 99 & 99 & 99 & 99 & 100 & 100 & 100 & & & & 99 & 100 & 99 & 99 & 99 & 99 & 99 & & & \\
\hline T. thermosaccharolyticum M0795 & 99 & 99 & 98 & 95 & 98 & 100 & 100 & & & 58 & & 99 & 99 & 95 & 99 & 99 & 99 & & & \\
\hline T. saccharolyticum JW/SL-YS485 & & & & & & & & 0 & 0 & 93 & & 92 & 90 & 90 & 97 & 94 & 94 & & & \\
\hline T. saccharolyticum NTOU1 & & & & & & & & 0 & 0 & & 98 & 92 & 92 & 91 & 98 & 94 & 94 & & & \\
\hline T. xylanolyticuml $\mathrm{X}-11$ & & & & & & & & 0 & 0 & 92 & & 92 & 92 & 91 & 97 & 94 & 94 & & & \\
\hline T. aotearoense SCUT27 & & & & & & & & 0 & 0 & 93 & & 92 & 90 & 90 & 97 & 94 & 94 & & & \\
\hline Thermoanaerobacterium sp. PSU-2 & & & & & & & & 0 & 0 & & & 91 & 91 & 90 & 98 & 93 & 93 & & & \\
\hline Thermoanaerobacterium sp. RBIITD & 77 & 96 & 91 & 96 & 88 & 90 & 82 & & & 58 & 67 & 89 & 89 & 84 & 55 & 87 & 87 & & & \\
\hline Clostridium acetobutylicum ATCC 824 & 58 & 72 & 66 & 58 & 69 & 71 & & 0 & 0 & & & & & 45 & 53 & 63 & 72 & 0 & 0 & 0 \\
\hline
\end{tabular}

* Numbers indicate percentage of protein sequence identity with the corresponding protein of strain GSU5.

Red cells indicate that the gene is present in the corresponding strain and absent in GSU5.

Blank cells indicate absence of the gene in the corresponding strain.

Genes code for the proteins are indicated as follows, $c r t$ : crotonase; $b c d$ : butyryl-CoA dehydrogenase; etfAB: electron transfer flavoprotein; $h b d: 3$-hydroxybutyryl-CoA dehydrogenase;

thl: acetyl-CoA C-acetyltransferase; but: butyryl-CoA: acetate-CoA transferase; $p t b$ : phosphotrans butyrylase; buk: butyrate kinase; ald: aldehyde dehydrogenase; adh: alcohol dehydrogenase;

$b d h$ : butanol dehydrogenase; $a d h E$ : bifunctional aldehyde/ alcohol dehydrogenase; pta: phosphotrans acetylase; $a k$ : acetate kinase; $c t f A B$ : acetoacetyl coenzyme A: acetate/butyrate:coenzyme A transferase; adc: acetoacetate decarboxylase. Accession numbers for each genome are indicated in Table 1.

indicated that AdhE was responsible for the synthesis of n-butanol from butyryl-CoA and ethanol from acetyl-CoA (Bhandiwad et al., 2014). All strains also carried genes coding for other dehydrogenases including Bhd that could also have a role in the synthesis of alcohols in Thermoanaerobacterium. Interestingly, one of the dehydrogenases, adh3, was highly conserved in all genomes, located upstream from genes coding for a NADH-dependent reduced ferredoxin: NADP oxidoreductase $(n f n A B)$.

In recent years, analysis of the genome of several strains of $T$. thermosaccharolyticum revealed important differences in the biosynthesis of butanol and butyrate when compared to the ABE pathway known in the well characterized C. acetobutylicum (Jones and Woods, 1986). Previous reports indicated that the gene coding for the acetoacetate decarboxylase (adc) was absent in T. thermosaccharolyticum M5 (Jiang et al., 2018), and that both adc and $\operatorname{ctf} A B$ (that codes for the butyrate-acetoacetate CoA-transferase subunits $\mathrm{A}$ and B) were absent in T. thermosaccharolyticum TG57 (Li et al., 2018), indicating that these bacteria were unable to produce acetone. These genes were searched in the genomes of $T$. thermosaccharolyticum GSU5 and in all available Thermoanaerobacterium genomes using the genes from $C$. acetobutylicum as queries. None of the genomes analyzed carried $c t f A B$ or $a d c$ (Table 2) indicating that none of the strains analyzed would be able to produce acetone during fermentation (Fig. 3). Since the analysis involved all available Thermoanaerobacterium genomes representing half of the known species, these results suggest that this is a common trait in this genus.

Butyrate production has been reported for several T. thermosaccharolyticum strains (Freier-Schröder et al., 1989; Li et al., 2018), and is the main metabolite produced from most carbon sources by both strains tested in this work. Among the known butyrate producing pathways, the most common is the acetyl-CoA pathway, that has two variants: i) the two-step conversion catalyzed by the phosphotransbutyrylase (Ptb) and butyrate kinase (Buk) with a phosphorylated intermediate that allows the formation of ATP, commonly found in bacteria that have the ABE pathway, and ii) the one step conversion of butyryl-CoA to butyrate catalyzed by a butyryl-CoA:acetate-CoA transferase (But) (Vital et al., 2014). Only the one step pathway seems to be performed by the strain GSU5 and all other T. thermosaccharolyticum strains, as they carry but (denominated ach in T. thermosaccharolyticum TG57), and not $p t b$ or buk (Bhandiwad et al., 2013; Li et al., 2018) (Fig. 3). The two-step pathway has been proposed to exist in the strain M5 (Jiang et al., 2018) but its genome does not carry genes coding for Ptb or Buk.

The one step conversion of butyryl-CoA to butyrate has been extensively studied in C. kluyveri, that seems to compensate for the lack of the ATP producing step by means of an electron bifurcating mechanism involving the crotonyl-CoA reductase that couples the reduction of crotonyl-CoA to the reduction of ferredoxin using NADH as the electron donor for both reactions. The reduction of crotonyl-CoA to butyryl-CoA is catalyzed by the cytoplasmic butyryl-CoA dehydrogenase complex, coded by $b c d$ and etf $A B$, while the reduction of the ferredoxin is catalyzed by $\mathrm{NfnAB}$, a NADH-dependent reduced ferredoxin:NADP oxidoreductase (Wang et al., 2010). These genes are present in all strains of $T$. thermosaccharolyticum and in Thermoanaerobacterium sp. RBIITD that have the capability to produce butanol and butyrate (Table 2). Furthermore, the ferredoxindependent activity of the butyryl-CoA dehydrogenase was experimentally demonstrated in T. thermoanaerobacterium DSM 571 (Bhandiwad et al., 2014). Based on this information, it can be hypothesized that all butanol producing Thermoanaerobacterium are able to obtain energy during the one step butyrate synthesis through the ferredoxin mediated electron bifurcation mechanism (Fig. 3). In contrast, genes coding for Ptb and Buk were identified in $T$. xylanolyticum, $T$. saccharolyticum, $T$. aotearoense, and Thermoanaerobacterium sp. PSU-2. These strains lack genes needed for butanol synthesis (bcs operon), and are also devoid of genes coding for the cytoplasmic butyryl-CoA dehydrogenase complex (bcd and etfAB), suggesting that they are unable to synthesize either butanol or butyrate. In these microorganisms, $p b t$ and $b u k$ are clustered together with a gene that codes for a leucine/valine/phenylalanine dehydrogenase. This genetic organization has been previously observed in Bacillus megaterium. In this organism, Ptb expression was induced in the presence of valine and isoleucine, and the enzyme could use butyryl-CoA and 2-methyl-propionyl CoA as substrates (Vazquez et al., 2001). In B. subtilis, these genes are part of the $b k d$ operon, involved in the degradation of branched chain amino- 


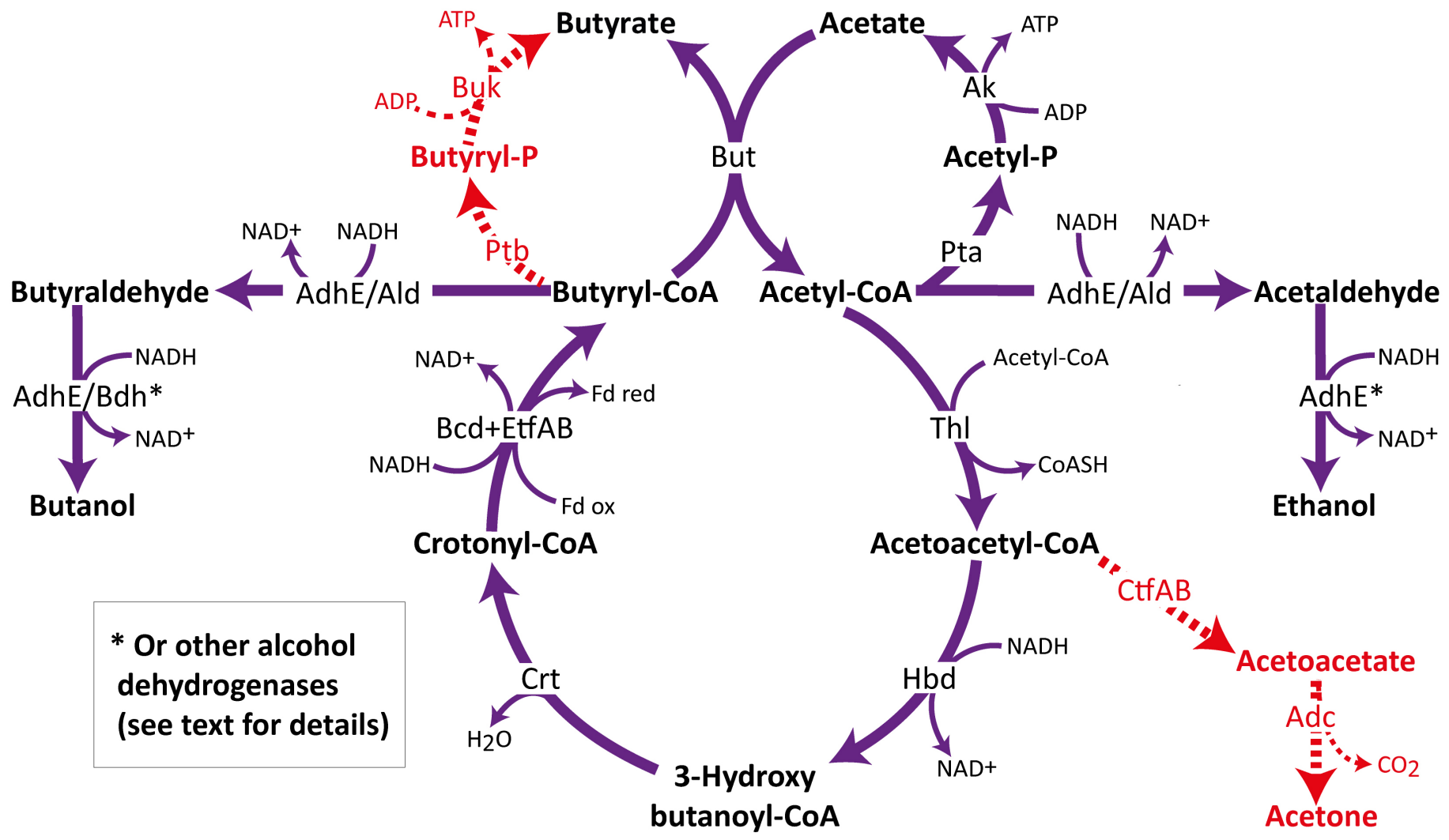

Fig. 3. Proposed main metabolic pathways in T. thermosaccharolyticum.

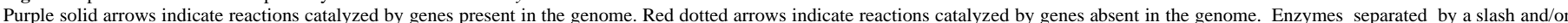

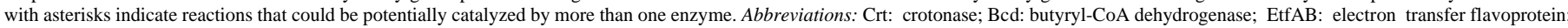

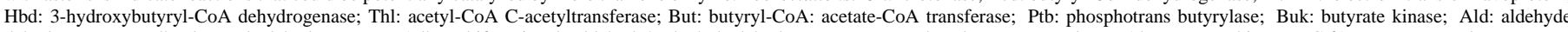

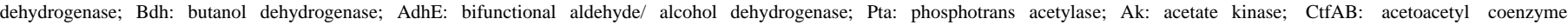
A:acetate/butyrate:coenzyme A transferase; Adc: acetoacetate decarboxylase; Fd red: reduced ferredoxin; Fd ox: oxidized ferredoxin.

acids (Debarbouille et al., 1999). It is possible that in T. xylanolyticum, T. saccharolyticum, Thermoanaerobacterium $\mathrm{sp}$. PSU-2, and T. aotearoense, Ptb and Buk could be involved in branched chain amino-acid degradation as in Bacillus.

\subsection{Production of metabolites from different carbon sources}

The synthesis of solvents and acids by T. thermosaccharolyticum GSU5 was analyzed in cultures grown using different substrates in $5 \mathrm{~mL}$ tubes, and compared with the type strain of the species, DSM 571. Both strains grew well on several monosaccharides: glucose, xylose, arabinose, and galactose, and also on the disaccharides, sucrose and cellobiose. They grew slightly more when using fructose that on pentoses and other hexoses, and also showed a modest preference for cellobiose compared to sucrose (despite their specific epithet).

Ethanol was the most abundant alcohol, and butanol was also observed in all cultures in lower amounts. Acetone was not produced, as previously reported for the butanol producing strains RBIITD and TG57 (Biswas et al., 2018; Li et al., 2018). Among the acids, butyrate was the most abundant, followed by acetate and lower amounts of lactate (Fig. 4). The relative production of the metabolites depended on the substrate used, and some differences were observed between the strains. The main product of GSU5 was butyrate in all the conditions tested, ranging from 0.93 to $2.07 \mathrm{~g} / \mathrm{L}$, while DSM 571 synthesized butyrate as a main product $(0.99$ to $1.35 \mathrm{~g} / \mathrm{L})$ in all cultures except those using glucose and xylose, in which similar amounts of ethanol and butyrate were observed (Fig. 4). Both strains produced much more ethanol than butanol. GSU5 produced between 0.12 and $0.73 \mathrm{~g} / \mathrm{L}$ ethano and 0.005 to $0.048 \mathrm{~g} / \mathrm{L}$ butanol, with the highest amount of butanol produced in sucrose. DSM 571 produced between 0.25 and $1.25 \mathrm{~g} / \mathrm{L}$ ethanol and 0.014 to $0.034 \mathrm{~g} / \mathrm{L}$ butanol with the highest amount of butanol obtained in glucose.

Strain GSU5 produced 3.2 times more butanol than DSM 571 in sucrose (0.048 vs. $0.015 \mathrm{~g} / \mathrm{L} ; \mathrm{p}<0.05)$, and also accumulated more butanol than DSM 571 in arabinose, while the opposite was observed in fructose and cellobiose, in which strain DSM 571 produced more butanol than GSU5. When ethanol production was compared, strain DSM 571 produced a greater concentration of ethanol than GSU5 in all hexoses and in xylose, in which the highest amount was observed $(0.98 \mathrm{~g} / \mathrm{L})$, while GSU5 accumulated more ethanol in arabinose and with the disaccharides sucrose and cellobiose, with the maximum production in this last carbon source $(0.73 \mathrm{~g} / \mathrm{L})$

These results are similar to those obtained in previous studies performed using T. thermosaccharolyticum DSM 571 grown on cellobiose (Bhandiwad et al., 2013), and also using strain M5 grown on xylan (Jiang et al., 2018). In contrast, Li et al. (2018) report that $T$. thermosaccharolyticum TG57 produced butyrate, acetate, and butanol, but no ethanol, when grown using glucose, cellobiose, cellulose or xylan, in spite of the fact that it has all enzymes required for the synthesis of both alcohols. 

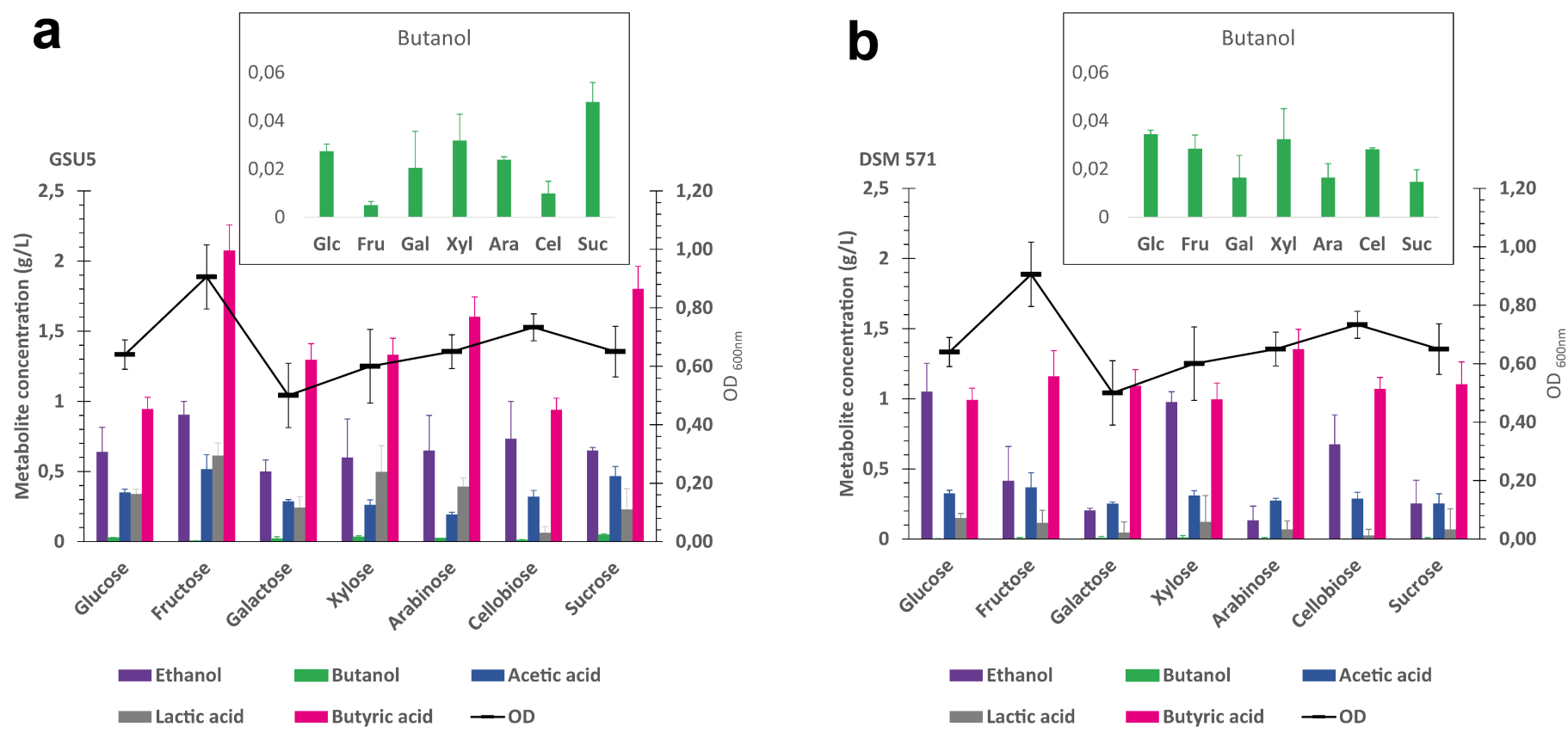

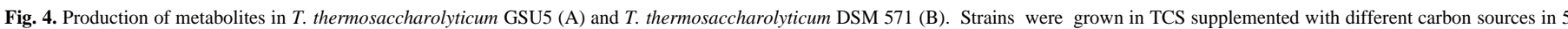
$\mathrm{mL}$ Hungate tubes under anaerobic conditions for $48 \mathrm{~h}$. Results represent the mean value \pm standard deviation of three independent replicates.

\subsection{Bioreactor cultures}

Strain GSU5 was grown in bioreactor batch cultures using glucose or xylose as carbon sources in order to analyze solvent production in a larger scale. Several tests were performed to determine the best $\mathrm{pH}$ conditions for growth and solvent production, since previous studies had indicated that solvent production was enhanced by high $\mathrm{pH}$ in other $T$. thermosaccharolyticum strains (Jiang et al., 2018). Preliminary tests in glucose cultures with initial starting pH of 6.7 or 7.5 did not allow adequate growth, so all cultures were performed with an initial $\mathrm{pH}$ of 7, and $\mathrm{pH}$ was controlled to prevent values lower than 5 . Sugars were added at an initial concentration of $10 \mathrm{~g} / \mathrm{L}$, and replenished after $17 \mathrm{~h}$ by adding half the initial amount to avoid sugar depletion.

Growth was more vigorous in glucose cultures, achieving 52\% more biomass than when using xylose $(1.9 v s .1 .0 \mathrm{~g} / \mathrm{L})$. Solvent production was also higher in glucose, while xylose cultures produced more acids than solvents (Fig. 5). Butyric acid remained the main product in xylose cultures, but glucose cultures produced slightly more ethanol than butyrate. The final butanol concentration obtained was $0.33 \pm 0.01 \mathrm{~g} / \mathrm{L}$ in glucose and $0.26 \pm$ a

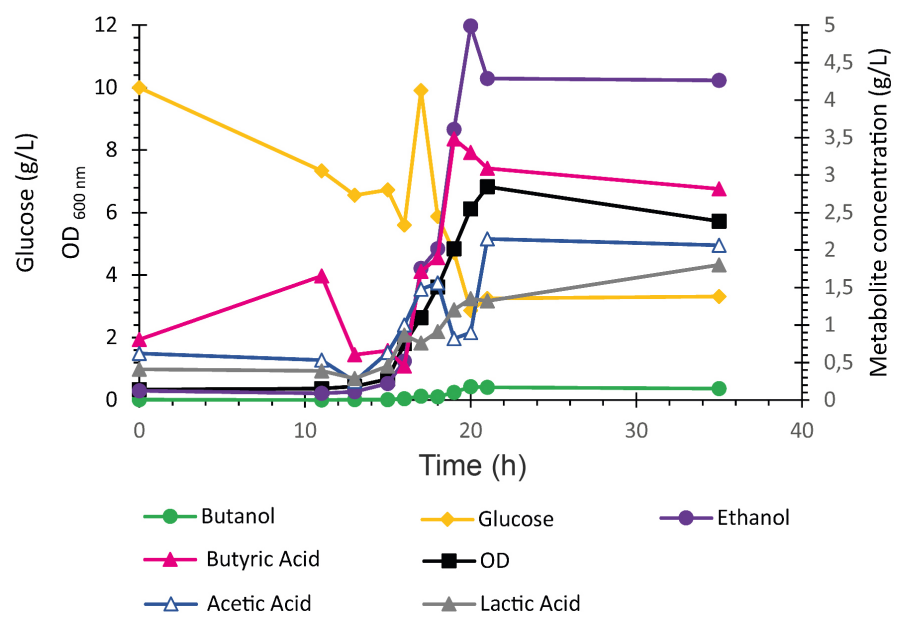

b

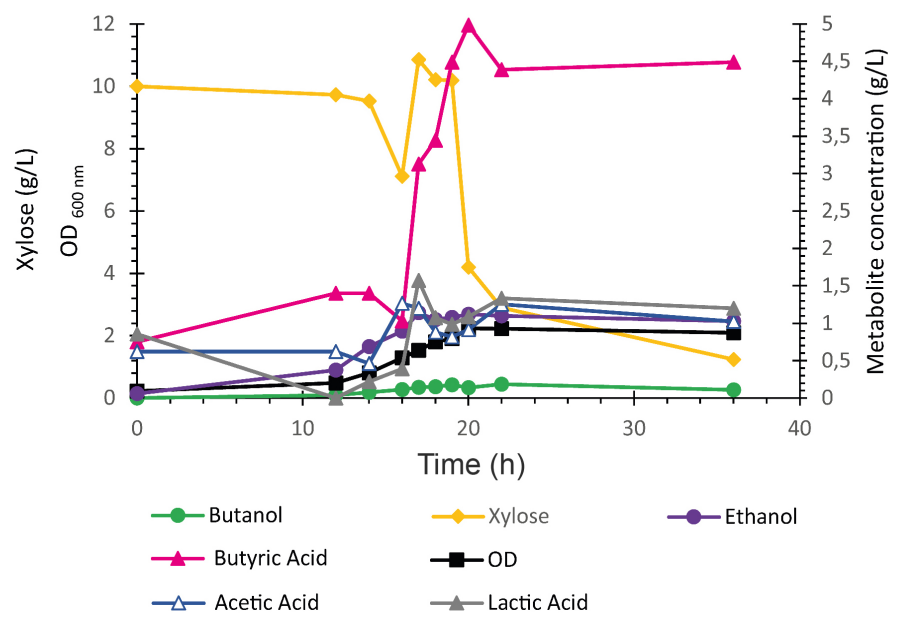

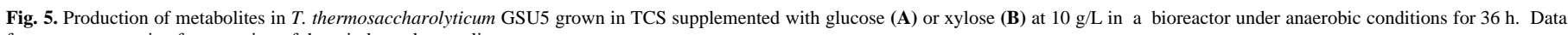
from a representative fermentation of three independent replicates. 
Table 3.

Fermentation products of $T$. thermosaccharolyticum GSU5.*

\begin{tabular}{|c|c|c|c|c|c|c|c|c|}
\hline \multirow{2}{*}{$\begin{array}{l}\text { Fermentation } \\
\text { Product }\end{array}$} & \multicolumn{2}{|c|}{ Product concentration $(\mathrm{g} / \mathrm{L})$} & \multicolumn{2}{|c|}{ Yield $^{\mathrm{a}}(\mathrm{g} / \mathrm{g})$} & \multicolumn{2}{|c|}{$\operatorname{Yield}^{\mathrm{b}}(\mathrm{mol} / \mathrm{mol})$} & \multicolumn{2}{|c|}{ Volumetric productivity ${ }^{\mathrm{c}} \mathrm{g} /(\mathrm{L} . \mathrm{h})$} \\
\hline & Glu & Xyl & Glu & Xyl & Glu & Xyl & Glu & Xyl \\
\hline Butanol & $0.33 \pm 0.10^{* *}$ & $0.26 \pm 0.15$ & $0.034 \pm 0.008$ & $0.022 \pm 0.007$ & $0.09 \pm 0.02$ & $0.05 \pm 0.01$ & $0.015 \pm 0.004$ & $0.013 \pm 0.006$ \\
\hline Ethanol & $4.35 \pm 0.06$ & $1.06 \pm 0.05$ & $0.46 \pm 0.07$ & $0.08 \pm 0.01$ & $1.8 \pm 0.1$ & $0.31 \pm 0.05$ & $0.19 \pm 0.01$ & $0.050 \pm 0.002$ \\
\hline Butyrate & $3 \pm 1$ & $6 \pm 3$ & $0.39 \pm 0.24$ & $0.33 \pm 0.19$ & $0.8 \pm 0.3$ & $0.6 \pm 0.3$ & $0.12 \pm 0.08$ & $0.28 \pm 0.09$ \\
\hline Acetate & $2.3 \pm 0.9$ & $0.96 \pm 0.2$ & $0.13 \pm 0.08$ & $0.10 \pm 0.07$ & $0.5 \pm 0.2$ & $0.15 \pm 0.07$ & $0.11 \pm 0.04$ & $0.05 \pm 0.01$ \\
\hline Lactate & $1.1 \pm 0.3$ & $1.2 \pm 0.8$ & $0.15 \pm 0.07$ & $0.09 \pm 0.07$ & $0.22 \pm 0.06$ & $0.2 \pm 0.1$ & $0.05 \pm 0.01$ & $0.06 \pm 0.04$ \\
\hline Biomass & $1.9 \pm 0.7$ & $1.0 \pm 0.5$ & $0.19 \pm 0.09$ & $0.09 \pm 0.05$ & - & - & - & - \\
\hline
\end{tabular}

* Cultures were grown in TSC medium supplemented with glucose or xylose at 10/L in a bioreactor under anaerobic conditions for $36 \mathrm{~h}$.

** Results represent means \pm the standard deviations corresponding to three independent cultures (Glu: Glucose and Xyl: xylose).

a Yield: g of product/g of substrate

${ }^{\mathrm{b}}$ Yield: $\mathrm{mol}$ of product $/ \mathrm{mol}$ of substrate

${ }^{c}$ Volumetric productivity: g of product/(time . volume)

$0.02 \mathrm{~g} / \mathrm{L}$ in xylose, while the final ethanol concentration was $4.35 \pm 0.06 \mathrm{~g} / \mathrm{L}$ in glucose and $1.06 \pm 0.05 \mathrm{~g} / \mathrm{L}$ in xylose (Table 3 ).

As expected, the bioreactor cultures corresponding to both sugars had a much higher biomass and solvent production that the $5 \mathrm{~mL}$ tube cultures. Although the main products were the same as observed in tube cultures, the relative amounts of acids and alcohols varied. A higher relative amount of butanol was observed with both substrates when all major metabolites were considered, showing a slight increase in carbon fluxes towards butanol in bioreactor cultures (Fig. 6). When cultures grown using glucose were

\section{a Glucose Huntage Tubes}

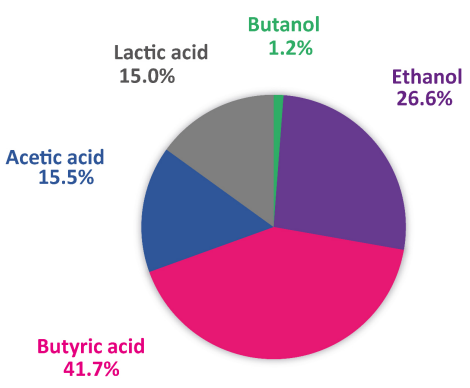

C Xylose Huntage Tubes

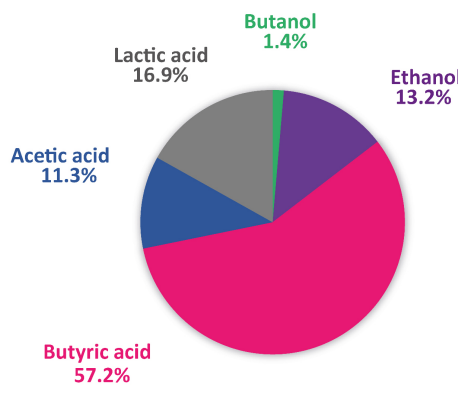

compared to tube cultures, solvent production was observed to increase more than biomass, with the most important increase measured in butanol production. While an 8-fold change was recorded in biomass $(1.78 \mathrm{vs.} 0.22$ $\mathrm{g} / \mathrm{L}$ ), final concentrations of ethanol and butanol increased by 10 and 14 times, respectively, so that the amount of alcohols produced in the bioreactor was similar to that of acids (Fig. 6). Results obtained with xylose were different, as a 6-fold increase in biomass (1.04 vs. $0.20 \mathrm{~g} / \mathrm{L})$ was accompanied by a similar increase in butanol concentration, while ethanol concentration only increased by 1.5 folds when the bioreactor cultures were compared with the $5 \mathrm{~mL}$ cultures (Fig. 6).
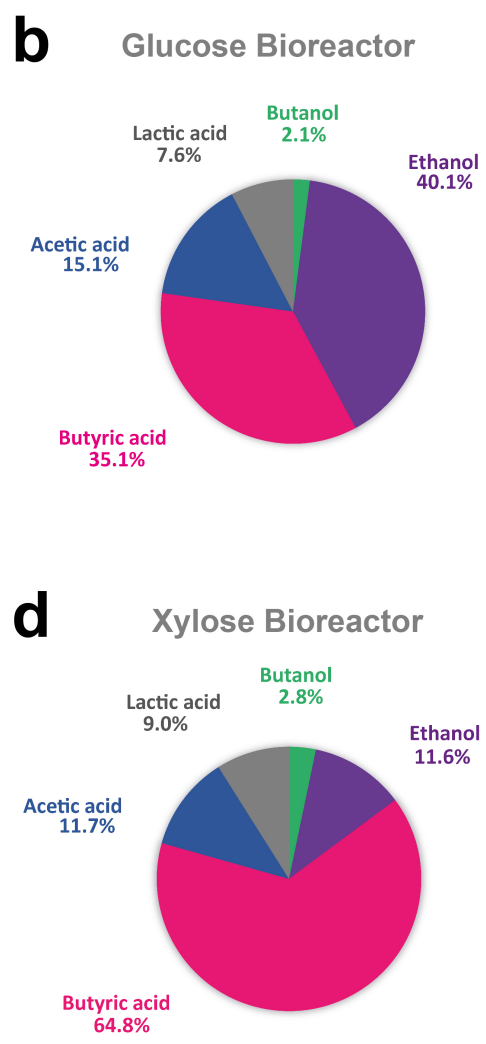

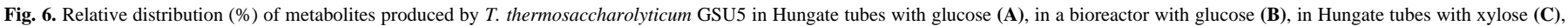
and in a bioreactor with xylose (D). 
These results could suggest that in higher density cultures, carbon flow towards the synthesis of alcohols increases contributing to the re-oxidation of excess NADH or NADPH, thus favoring the production of alcohols over acids.

Solventogenic anaerobes like the broadly studied model bacterium $C$. acetobutylicum have a fermentation behavior characterized by two distinct phases: formation of acids during the first phase followed by a solventogenic phase in which growth slows down, and solvents are produced (AmadorNoguez et al., 2011). When the dynamics of acids and alcohols production was analyzed in $T$. thermosaccharolyticum GSU5, metabolite synthesis was observed to accompany growth, and no clear solventogenic phase could be distinguished. This had been reported for T. thermosaccharolyticum M5 (Jiang et al., 2018) and careful observation of metabolite curves displayed in studies carried out with different solventogenic Thermoanaerobacterium strains show that in all cases alcohols and acids are synthesized throughout growth. This can be clearly perceived in an early work performed using strain DSM 571 (FreierSchröder et al., 1989) and in the metabolite curves shown in studies that analyze the production of hydrogen in different strains of $T$. thermosaccharolyticum (Cao et al., 2009 and 2014; Khamtib and Reungsang, 2012), using both sugars or lignocellulosic biomass for growth. These results suggest that solventogenesis in Thermoanaerobacterium is not subject to the same regulatory mechanisms described for the $\mathrm{ABE}$ metabolism in Clostridium.

\section{Conclusions}

Several species of Thermoanaerobacterium have been studied for the production of different bioproducts. Among them, T. thermosaccharolyticum seems to be the most promising, and different strains have been analyzed as candidates for the production of hydrogen (Cao et al., 2009 and 2014), ethanol (Bhandiwad et al., 2013 and 2014; Jiang et al., 2018) and 1,2 propanediol (Cameron and Cooney, 1986; Altaras et al., 2001) from several carbon sources, including lignocellulosic biomass. T. thermosaccharolyticum GSU5 is able to produce ethanol and butanol from a wide variety of substrates, including hexoses, pentoses and the discacharides sucrose and cellobiose. Analysis of the genome of $T$. thermosaccharolyticum GSU5 and comparison with other members of the genus enabled new insights into the particular metabolic characteristics of these bacteria, leading to a detailed description of the metabolic routes present in Thermoanaerobacterium, with clear differences between butanol producing and non-butanol producing strains. The metabolism of the butanol producing Thermoanaerobacterium differs from the metabolism of the well-known butanol producer $C$. acetobutylicum. Among the most important differences are the lack of acetone synthesis, a different butyrate production pathway, and a different dynamic of solvent and acid synthesis. Knowledge on their physiology and unique metabolic properties will enable the use of these microorganisms to obtain biotechnologically relevant bioproducts in sustainable and environmentally friendly processes.

\section{Acknowledgements}

We wish to thank Dr. Beatriz Méndez for her expert advice and Dr. Laura Raiger Iustman for allowing us to use the bioreactor. M.J.P. and J.R. are career investigators from Consejo Nacional de Investigaciones Científicas y Técnicas (CONICET, Argentina). R.D.P., D.E.E., and D.S.A. hold doctoral fellowships from the CONICET.

\section{References}

[1] Altaras, N.E., Etzel, M.R., Cameron, D.C., 2001. Conversion of sugars to 1,2-propanediol by Thermoanaerobacterium thermosaccharolyticum HG-8. Biotechnol. Progr. 17(1), 52-56

[2] Amador-Noguez, D., Brasg, I.A., Feng, X.J., Roquet, N., Rabinowitz, J.D., 2011. Metabolome remodeling during the acidogenic-solventogenic transition in Clostridium acetobutylicum. Appl. Environ. Microbiol. 77(22), 7984-7997

[3] Amiri, H., Azarbaijani, R., Yeganeh, L.P., Fazeli, A.S., Tabatabaei, M., Salekdeh, G.H., Karimi, K., 2016. Nesterenkonia sp. strain F, a halophilic bacterium producing acetone, butanol and ethanol under aerobic conditions. Sci. Rep. 6(1), 1-10.
[4] Auch, A.F., Klenk, H.P., Göker, M., 2010. Standard operating procedure for calculating genome-to-genome distances based on highscoring segment pairs. Stand. Genomic Sci. 2(1), 142-148.

[5] Berezina, O.V., Brandt, A., Yarotsky, S., Schwarz, W.H., Zverlov, V.V., 2009. Isolation of a new butanol-producing Clostridium strain high level of hemicellulosic activity and structure of solventogenesis genes of a new Clostridium saccharobutylicum isolate. Syst. Appl. Microbiol. 32(7), 449-459.

[6] Bhandiwad, A., Guseva, A., Lynd, L.R., 2013. Metabolic engineering of Thermoanaerobacterium thermosaccharolyticum for increased nbutanol production for $\mathrm{n}$-butanol production. Adv. Microbiol. 3, 4651.

[7] Bhandiwad, A., Shaw, A.J., Guss, A., Guseva, A., Bahl, H., Lynd, L.R., 2014. Metabolic engineering of Thermoanaerobacterium saccharolyticum for n-butanol production. Metab. Eng. 21, 17-25.

[8] Biswas, R., Huntemann, M., Clum, A., Pillay, M., Palaniappan, K. Varghese, N., Gussc, A.M., 2018. Complete genome sequence of Thermoanaerobacterium sp. strain RBIITD, a butyrate- and butanolproducing thermophile. Genome Announc. 6(2), e01411-17.

[9] Cameron, D.C., Cooney, C.L., 1986. A novel ferementation: the production of $\mathrm{R}(-)-1,2$-propanediol and acetol by Clostridium Thermosaccharolyticum. Nat. Biotechnol. 4(7), 651-654.

[10] Cao, G., Ren, N., Wang, A., Lee, D.J., Guo, W., Liu, B., Feng, Y., Zhao, Q., 2009. Acid hydrolysis of corn stover for biohydrogen production using Thermoanaerobacterium thermosaccharolyticum W16. Int. J. Hydrogen Energy. 34(17), 7182-7188.

[11] Cao, G.L., Zhao, L., Wang, A.J., Wang, Z.Y., Ren, N.Q., 2014 Single-step bioconversion of lignocellulose to hydrogen using novel moderately thermophilic bacteria. Biotechnol. Biofuels. 7(1), 82.

[12] Debarbouille, M., Gardan, R., Arnaud, M., Rapoport, G., 1999. Role of bkdR, a transcriptional activator of the SigL-dependent isoleucine and valine degradation pathway in Bacillus subtilis. J. Bacteriol. 181(7), 2059-2066

[13] Demain, A.L., Newcomb, M., Wu, J.D., 2005. Cellulase, clostridia and ethanol. Microbiol. Mol. Biol. Rev. 69(1), 124-154.

[14] Dürre, P., 2007. Biobutanol: an attractive biofuel. Biotechnol. J Healthcare Nutr. Technol. 2(12), 1525-1534.

[15] Freier-Schröder, D., Wiegel, J., Gottschalk, G., 1989. Butanol formation by Clostridium thermosaccharolyticum at neutral $\mathrm{pH}$ Biotechnol. Lett. 11(11), 831-836.

[16] Hill, J., Nelson, E., Tilman, D., Polasky, S., Tiffany, D., 2006 Environmental, economic, and energetic costs and benefits of biodiesel and ethanol biofuels. Proc. Natl. Acad. Sci. 103(30), 1120611210 .

[17] Hungate, R.E., 1950. The anaerobic mesophilic cellulolytic bacteria Bacteriol. Rev. 14(1), 1.

[18] Jiang, Y., Guo, D., Lu, J., Dürre, P., Dong, W., Yan, W., Zhang, W. Ma, J., Jiang, M., Xin, F., 2018. Consolidated bioprocessing of butanol production from xylan by a thermophilic and butanologenic Thermoanaerobacterium sp. M5. Biotechnol Biofuels. 11(1), 1-14.

[19] Jones, D.T., Woods, D.R., 1986. Acetone-butanol fermentation revisited. Microbiol. Rev. 50(4), 484-524.

[20] Khamtib, S., Reungsang, A., 2012. Biohydrogen production from xylose by Thermoanaerobacterium thermosaccharolyticum KKU19 isolated from hot spring sediment. Int. J. Hydrogen Energy. 37(17), 12219-12228.

[21] Lamed, R., Zeikus, J.G., 1980. Ethanol production by thermophilic bacteria: relationship between fermentation product yields of and catabolic enzyme activities in Clostridium thermocellum and Thermoanaerobium brockii. J. Bacteriol. 144(2), 569-578

[22] Li, T., Zhang, C., Yang, K.L., He, J., 2018. Unique genetic cassettes in a Thermoanaerobacterium contribute to simultaneous conversion of cellulose and monosugars into butanol. Sci Adv. 4(3), e1701475.

[23] Lynd, L.R., Weimer, P.J., Van Zyl, W.H., Pretorius, I.S., 2002. Microbial cellulose utilization: fundamentals and biotechnology. Microbiol. Mol. Biol. Rev. 66(3), 506-577.

[24] Mendez, B.S., Pettinari, M.J., Ivanier, S.E., Ramos, C.A., Siñeriz, F. 1991. Clostridium thermopapyrolyticum sp. nov., a cellulolytic thermophile. Int. J. Syst. Evol. Microbiol. 41(2), 281-283. 
[25] Onyenwoke, R.U., Wiegel, J., 2015. Thermoanaerobacter. Bergey's Manual of Systematics of Archaea and Bacteria, pp.1-29.

[26] Overbeek, R., Olson, R., Pusch, G.D., Olsen, G.J., Davis, J.J., Disz, T., Edwards, R.A., Gerdes, S., Parrello, B., Shukla, M., Vonstein, V., 2014. The SEED and the rapid annotation of microbial genomes using subsystems technology (RAST). Nucleic Acids Res.42(D1), D206-D214.

[27] Panitz, J.C., Zverlov, V.V., Pham, V.T.T., Stürzl, S., Schieder, D., Schwarz, W.H., 2014. Isolation of a solventogenic Clostridium sp. strain: fermentation of glycerol to n-butanol, analysis of the bcs operon region and its potential regulatory elements. Syst. Appl. Microbiol. 37(1), 1-9.

[28] Richter, M., Rosselló-Móra, R., Oliver Glöckner, F., Peplies, J., 2016. JSpeciesWS: a web server for prokaryotic species circumscription based on pairwise genome comparison. Bioinformatics. 32(6), 929-931.

[29] Romano, I., Dipasquale, L., Orlando, P., Lama, L., d’Ippolito, G., Pascual, J., Gambacorta, A, 2010. Thermoanaerobacterium thermostercus sp. nov., a new anaerobic thermophilic hydrogen-producing bacterium from buffalo-dung. Extremophiles. 14(2), 233-240.

[30] Shaw, A.J., Podkaminer, K.K., Desai, S.G., Bardsley, J.S., Rogers, S.R., Thorne, P.G., Hogsett D.A., Lynd, L.R, 2008. Metabolic engineering of a thermophilic bacterium to produce ethanol at high yield. Proc. Natl. Acad. Sci. U.S.A. 105(37), 13769-13774.

[31] Shaw, J.A., Covalla, S.F., Miller, B.B., Firliet, B.T., Hogsett, D.A., Herring, C.D, 2012. Urease expression in a Thermoanaerobacterium saccharolyticum ethanologen allows high titer ethanol production. Metab. Eng. 14(5), 528-532.
[32] Sompong, O., Khongkliang, P., Mamimin, C., Singkhala, A. Prasertsan, P., Birkeland, N.K., 2017. Draft genome sequence of Thermoanaerobacterium sp. strain PSU-2 isolated from thermophilic hydrogen producing reactor. Genomics Data. 12, 49-51.

[33] Sompong, O., Prasertsan, P., Karakashev, D., Angelidaki, I., 2008 Thermophilic fermentative hydrogen production by the newly isolated Thermoanaerobacterium thermosaccharolyticum PSU-2. Int. J. Hydrogen Energy. 33(4), 1204-1214.

[34] Tian, L., Papanek, B., Olson, D.G., Rydzak, T., Holwerda, E.K. Zheng, T., Zhou, J., Maloney, M., Jiang, N., Giannone, R.J., Hettich, R.L., 2016. Simultaneous achievement of high ethanol yield and titer in Clostridium thermocellum. Biotechnol. Biofuels. 9(1), 116.

[35] Vazquez, G.J., Pettinari, M.J., Méndez, B.S., 2001 Phosphotransbutyrylase expression in Bacillus megaterium. Curr. Microbiol. 42(5), 345-349.

[36] Vital, M., Howe, A.C., Tiedje, J.M., 2014. Revealing the bacterial butyrate synthesis pathways by analyzing (meta)genomic data. MBio 5(2), e00889-14.

[37] Wang, S., Huang, H., Moll, J., Thauer, R.K., 2010. NADP ${ }^{+}$reduction with reduced ferredoxin and $\mathrm{NADP}^{+}$reduction with $\mathrm{NADH}$ are coupled via an electron-bifurcating enzyme complex in Clostridium kluyveri. J. Bacteriol. 192(19), 5115-5123

[38] Wietzke, M., Bahl, H., 2012. The redox-sensing protein Rex, a transcriptional regulator of solventogenesis in Clostridium acetobutylicum. Appl. Microbiol. Biotechnol. 96(3), 749-761.

[39] Yamada, R., Hasunuma, T., Kondo, A., 2013. Endowing noncellulolytic microorganisms with cellulolytic activity aiming for consolidated bioprocessing. Biotechnol. Adv. 31(6), 754-763. 


\section{Supplementary Data}

Table S1.

Genome to genome comparisons of Thermoanaerobacterium sp. RBIITD with other species of Thermoanaerobacterium.

\begin{tabular}{|c|c|c|c|}
\hline Strain & Accession & DDH ${ }^{1}$ estimate & ANIb $^{2}$ \\
\hline Thermoanaerobacterium sp. RBIITD & LT906662.1 & - & - \\
\hline T. thermosaccharolyticum GSU5 & MINB01000001-MINB01000073 & $24.30 \pm 2.50 \%$ & $79.53 \%$ \\
\hline T. thermosaccharolyticum TG57 & СР016893.1 & $24.30 \pm 2.50 \%$ & $79.03 \%$ \\
\hline T. thermosaccharolyticum DSM 571 & CP002171 & $24.70 \pm 2,70 \%$ & $79.18 \%$ \\
\hline T. thermosaccharolyticum M5 & NKHD01000001-NKHD01000077 & $23.50 \pm 2.50 \%$ & $78.94 \%$ \\
\hline T. thermosaccharolyticum M0795 & NC_019970 & $24.50 \pm 2.50 \%$ & $79.19 \%$ \\
\hline T. saccharolyticum JW/SL-YS485 & СР003184.1 & $21.50 \pm 2,40 \%$ & $75.92 \%$ \\
\hline T. saccharolyticum NTOU1 & ВВКT01000001-ВВКТ01000101 & $23.30 \pm 2.50 \%$ & $77.39 \%$ \\
\hline T. xylanolyticum LX-11 & СР002739.1 & $21.30 \pm 2.40 \%$ & $76.16 \%$ \\
\hline T. aotearoense SCUT27 & AYSN01000000 & $21.40 \pm 2.40 \%$ & $76.19 \%$ \\
\hline T. sp. PSU-2 & MSQD00000000.1 & $21.30 \pm 2.70 \%$ & $76.16 \%$ \\
\hline
\end{tabular}

${ }^{1}$ DNA-DNA hybridization (DDH) values were estimated using the Genome-to-Genome Distance Calculator 2.1 (Species cutoff value: $70 \%$ ).

${ }^{2}$ ANIb: Average Nucleotide Identity based on BLAST (Species cutoff value $=95 \%$ ).

Table S2.

Genome to genome comparisons of Thermoanaerobacterium sp. PSU-2 with other species of Thermoanaerobacterium.

\begin{tabular}{|c|c|c|c|}
\hline Strain & Accession & DDH $^{1}$ estimate & $\mathbf{A N I b}^{2}$ \\
\hline Thermoanaerobacterium sp. PSU-2 & MSQD00000000.1 & - & - \\
\hline T. thermosaccharolyticum GSU5 & MINB01000001-MINB01000073 & $24.40 \pm 2,50 \%$ & $82.30 \%$ \\
\hline T. thermosaccharolyticum TG57 & СР016893.1 & $24.60 \pm 2,50 \%$ & $81.96 \%$ \\
\hline T. thermosaccharolyticum DSM 571 & CP002171 & $24.80 \pm 2.40 \%$ & $82.15 \%$ \\
\hline T. thermosaccharolyticum M5 & NKHD01000001-NKHD01000077 & $24.10 \pm 2.5 \%$ & $81.56 \%$ \\
\hline T. thermosaccharolyticum M0795 & NC_019970 & $58.30 \pm 2.80 \%$ & $81.93 \%$ \\
\hline T. saccharolyticum JW/SL-YS485 & СР003184.1 & $48.90 \pm 2.60 \%$ & $92.35 \%$ \\
\hline T. saccharolyticum NTOU1 & ВВКТ01000001-ВВКТ01000101 & $48.20 \pm 2.60 \%$ & $91.96 \%$ \\
\hline T. xylanolyticum LX-11 & СР002739.1 & $58.30 \pm 2,80 \%$ & $94.20 \%$ \\
\hline T. aotearoense SCUT27 & AYSN01000000 & $48.70 \pm 2,60 \%$ & $92.24 \%$ \\
\hline Thermoanaerobacterium sp. RBIITD & LT906662.1 & $21.30 \pm 2.70 \%$ & $76.68 \%$ \\
\hline
\end{tabular}

${ }^{1}$ DNA-DNA hybridization (DDH) values were estimated using the Genome-to-Genome Distance Calculator 2.1 (Species cutoff value: $70 \%$ ).

${ }^{2}$ ANIb: Average Nucleotide Identity based on BLAST (Species cutoff value $=95 \%$ ).

Table S3.

Locus tags of genes analyzed in this study.

https://www.biofueljournal.com/jufile?ar_sfile=1007034 